\title{
Straight waveguide to coaxial adapter of microwave and extremely high frequencies ranges
}

\author{
Stanislav Kozlov ${ }^{*}$, Sergei Pavlov, and Evgenij Horoshilov \\ MICRAN, Research \& Production Company, 51d, Kirova avenue, Tomsk, Tomsk reg., 634041, \\ Russian Federation
}

\begin{abstract}
The paper presents the results of electromagnetic modelling in the computer-aided design system and electrical parameters measurements of microwave band waveguide-to-coaxial adapters. Adapters are developed, manufactured and tested at Micran.
\end{abstract}

\section{Introduction}

In microwave transmission lines it is often necessary to switch from one type of transmission line (TL) to another, e.g. from coaxial line to a rectright-angle or a circular waveguide, or from coaxial line to microstrip, etc. Special devices called adapters are designed for these purposes.Adapters break the regularity of the transmission line, and therefore should be well matched on each of the inputs and should not reduce the electrical strength of the line[1]. In practice, coaxial and waveguide TL are most often used. Accordingly, waveguide to coaxial adapter (WCA) are used to join them. There are 2 basic types of WCA design: straight and right angle with different types of electrical coupling. Each of them has its advantages and disadvantages. For example, right-angle WCA has a simpler design than straight one. Also, due to the tuning elements, the right-angle WCA has better VSWR compared to the straight one. However, in complex microwave systems there are often situations when the usage of right-angle WCA is impossible because of their design. In the given paper the technique of modeling of straight WCA in the system of computer-aided design (CAD) is considered, as well as the results of measurement of straight WCA prototypes.

\section{Objects of design and research}

Table 1. Straight WCA manufactured by MICRAN

\begin{tabular}{|l|l|c|c|}
\hline \multicolumn{1}{|c|}{ Designation } & \multicolumn{1}{|c|}{$\begin{array}{c}\text { Coaxial type } \\
\text { connectors }\end{array}$} & $\begin{array}{c}\text { The section of the } \\
\text { waveguide, } \mathrm{mm}\end{array}$ & Frequency range, $\mathrm{GHz}$ \\
\hline PKV2-11-16-8 & Type N, male & $16 \times 8$ & $12.05-17.44$ \\
\hline PKV2-11R-16x8 & Type N, female & $16 \times 8$ & $12.05-17.44$ \\
\hline
\end{tabular}

\footnotetext{
*Corresponding author: kozlov@micran.ru
} 


\begin{tabular}{|l|l|c|c|}
\hline \multicolumn{1}{|c|}{ Designation } & \multicolumn{1}{c|}{$\begin{array}{c}\text { Coaxial type } \\
\text { connectors }\end{array}$} & $\begin{array}{c}\text { The section of the } \\
\text { waveguide, } \mathrm{mm}\end{array}$ & Frequency range, $\mathrm{GHz}$ \\
\hline PKV2-05-11-5,5 & Type 2,4 mm, male & $11 \times 5.5$ & $17,44-25.95$ \\
\hline PKV2-05R-11-5,5 & Type 2,4 mm, female & $11-5.5$ & $17.44-25.95$ \\
\hline PKV2-05-7,2-3,4 & Type 2,4 mm, male & $7.2-3.4$ & $25.95-37.50$ \\
\hline PKV2-05R-7,2-3,4 & Type 2,4 mm, female & $7.2-3.4$ & $25.95-37.50$ \\
\hline
\end{tabular}

The objects of design and research are the straight WCA given in Table 1. All the WCA have been designed, manufactured and tested at MICRAN [2].

\section{Modeling of straight WCA in CAD}

WCA combines two TL with different types of microwaves and impedances. Therefore, it can be stated that the WCA is a wave of type T transformer in the coaxial TL in the type H or $\mathrm{E}$ in the rectangular waveguide and it is so-called probe adapter. To excite H-type waves, a pin (probe) perpendicular to the longitudinal axis of the waveguide is inserted into the waveguide, and to excite E- type waves, a pin is inserted from the end of the waveguide parallel to the longitudinal axis of the waveguide (Fig.1) [3].

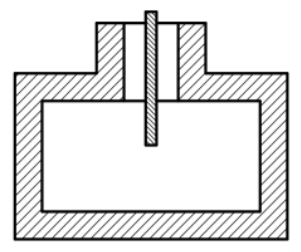

Fig. 1. Methods for exciting waves in a rectangular waveguide for H-type waves.

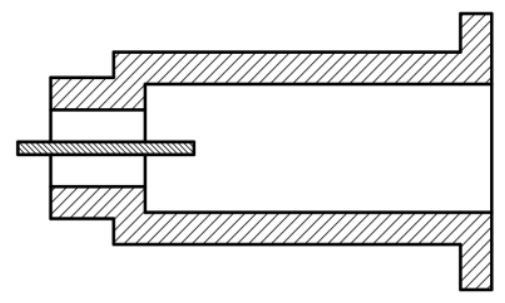

Fig. 2. Methods for exciting waves in a rectangular waveguide for E-type waves.

The second method of probe insertion is applied in the designed straight WCA. A step transformer is used to match the wave line impedances of the TL.

Modelled WCA are complex devices, which makes their design difficult. Therefore, during modeling in $\mathrm{CAD}$ it is rational to use a method of decomposition, which divides all the transition to a bundle of base elements, each of them is analyzed separately [4]. The initial data for the design were the frequency range, as well as types of coaxial connectors and waveguide flanges. The basic problem during modeling process is the calculation of the optimal geometry of the step transformer, and also waveguide and coaxial parts of WCA (figure 2). 


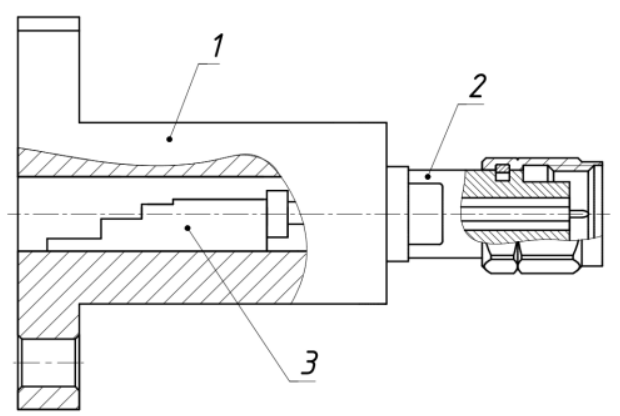

Fig. 3. Straight WCA design: 1 - Waveguide part of WCA, 2 - Coaxial part of WCA, 3 - Matching transformer.

When calculating the matching step transformer, it is necessary to know the wave line impedances of the matching coaxial $\left(Z_{C}\right)$ and waveguide $\left(Z_{W}\right)$ parts. The wave line impedance of the waveguide can be calculated by the equation (1):

$$
Z_{W}=120 \pi \frac{\lambda_{W}}{\lambda},
$$

where $\lambda_{\mathrm{W}}$ is wavelength in the waveguide, $\lambda$ is wavelength in coaxial TL.

Line impedance can also be represented as a sum of the active and reactive components by the equation (2):

$$
Z_{W}=\rho_{W}+j X_{W}
$$

where $\rho_{W}$ is active component, $X_{W}$ is imaginary component of impedance.

Matching is achieved by minimizing the reactive component of the wave line impedance $(X \rightarrow 0)$. Therefore, in order to match the waveguide and coaxial parts, it is necessary to match the active parts of the wave line impedance while minimizing their reactive components using a step transformer. The wavelengths in equation (1) are calculated using equations (3) and (4):

$$
\begin{gathered}
\lambda=\frac{c}{f_{a}}, \\
\lambda_{W}=\frac{\lambda}{\sqrt{1-\left(\frac{\lambda}{\lambda_{c r}}\right)^{2}}},
\end{gathered}
$$

where $c$ is constant speed of light, $f_{a}$ is average frequency of the frequency range; $\lambda_{c r}$ is critical wavelength in waveguide.

The critical wavelength of a rectangle waveguide is calculated by the equation (5):

$$
\lambda_{c r}=\frac{2}{\sqrt{\left(\frac{m}{a}\right)^{2}+\left(\frac{n}{b}\right)^{2}}}
$$

where $a$ is long wall of rectangle waveguide, $b$ is short wall of rectangle waveguide, $\mathrm{m}$ and $\mathrm{n}$ are determined by the main wave type propagating in the waveguide. 
After calculating the values of line impedances $Z_{C}$ and $Z_{W}$ using the method of undefined coefficients [5], the number of matching transformer steps is selected. Calculation showed that there must be at least four of them.

According to the decomposition method, modeling of devices in CAD was performed in 2 stages:

1) simulation of the coaxial connector;

2) simulation of WCA.

It was at the second stage where the optimal geometric dimensions of the matching step transformer were selected. During the modeling in CAD, it was confirmed that the number of steps of 4 is optimal.

\section{Measurement of prototypes electrical parameters}

According to the results of CAD modeling, samples of WCA were produced. Figure 4-6 shows comparative graphs of VSWR measurement results of experimental samples and calculated ratios. The measurement was carried out onf Agilent E8364B vector network analyzer. The graphs show a good convergence of results. The straight WCA developed have a low return loss $(\mathrm{VSWR}<1.15)$.

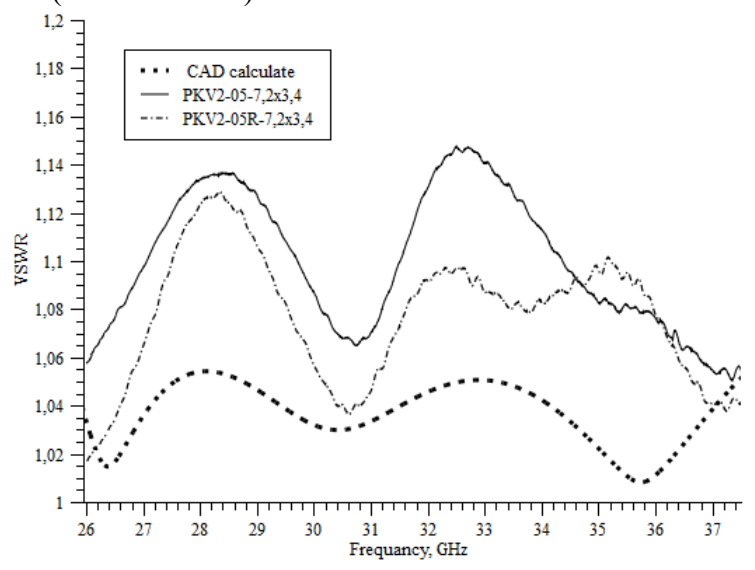

Fig. 4. Comparative graphs of VSWR measurement results of the prototypes and calculated value for the waveguide cross section of $7.2 \times 3.4 \mathrm{~mm}$.

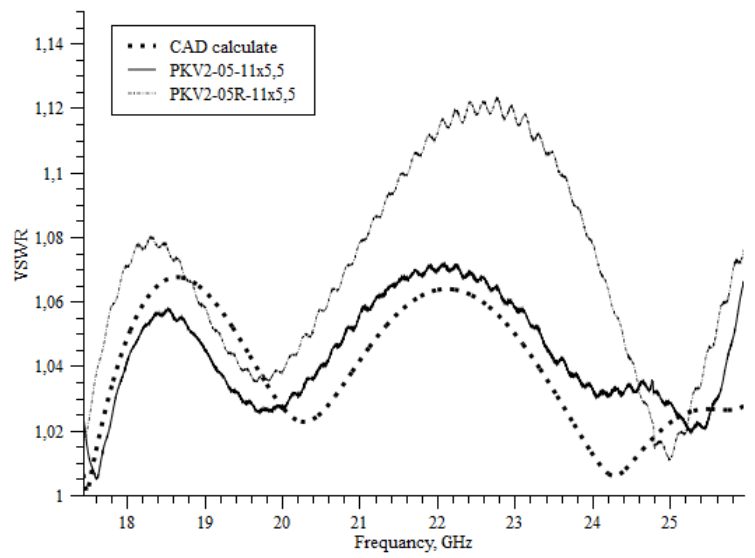

Fig. 5. Comparative graphs of VSWR measurement results of the prototype samples and calculated value for the waveguide cross section of $11 \times 5.5 \mathrm{~mm}$. 


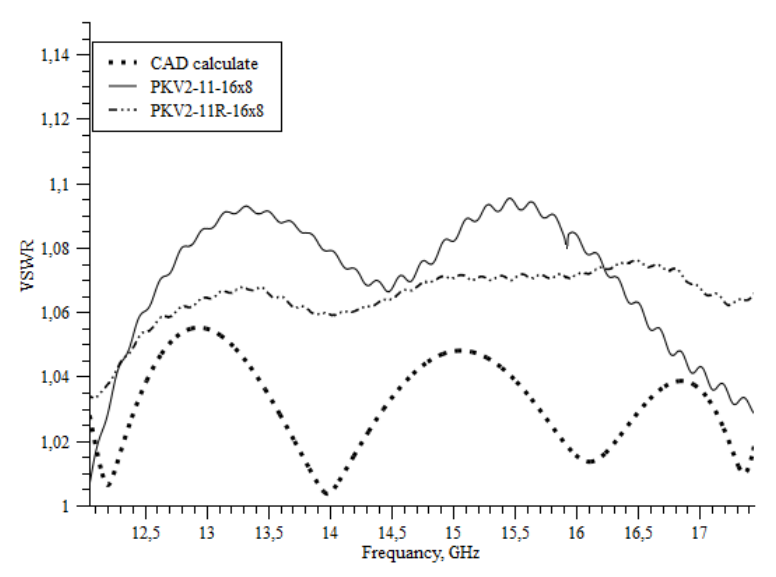

Fig. 6. Comparative graphs of VSWR measurement results of the prototype samples and calculated value for the waveguide cross section of $16 \times 8 \mathrm{~mm}$.

\section{Conclusions}

Straight WCA were designed and manufactured using the decomposition method. Electrical specifications of the prototypes are similar to the design ones, which confirm the relevance of this method.

Combined use of the method of undefined coefficients and CAD allowed to determine the optimal number of stages of matching step transformer, as well as to make an accurate calculation of its geometry.

Designed straight WCA have a low return loss (VSWR $<1.15$ ), allowing these devices to be positioned as instrument grade adapters.

\section{References}

1. Voskresenskij D.I., Antenny i ustrojstva SVCh (Radiotehnika, Moscow, 2006)

2. Katalog MICRAN Kontrol'no-izmeritel'naja apparatura i jelementy SVCh-trakta (Tomsk, 2019)

3. Bova N.T., Reznikov G.B., Antenny i ustrojstva SVCh (Vishha shkola, Kiev, 1982)

4. Sazonov D.M., Gridin A.N., Mishustin B.A., Ustrojstva SVCh (Vysshaja shkola, Moscow, 1981)

5. Fel'dshtejn A.L., Javich L.R., Sintez chetyrehpoljusnikov $i$ vos'mipoljusnikov na SVCh (Svjaz', Moscow, 1971) 